\title{
Developing and implementing a social prescribing initiative in primary care: insights into the possibility of normalisation and sustainability from a UK case study
}

\author{
Sandy Whitelaw ${ }^{1}$, Claire Thirlwall $^{2}$, Amy Morrison ${ }^{3}$, Jill Osborne ${ }^{3}$, Lisa Tattum ${ }^{3}$ and Sharon Walker ${ }^{4}$ \\ ${ }^{1}$ Lecturer Health \& Social Policy, School of Interdisciplinary Studies, University of Glasgow, Dumfries Campus, Dumfries, UK \\ ${ }^{2}$ Health \& Wellbeing Specialist, DG Health \& Wellbeing, NHS Dumfries and Galloway, Dumfries, UK \\ ${ }^{3}$ Research Assistant, School of Interdisciplinary Studies, University of Glasgow, Dumfries Campus, Dumfries, UK \\ ${ }^{4}$ Public Health Practitioner, Health Improvement Team, NHS Dumfries and Galloway, Dumfries, UK
}

\begin{abstract}
Aim: To conduct a process-based evaluation of the inception and early implementation of a social prescribing initiative (Healthy Connections Stewartry) in two UK General Practices. Background: Prescribing a range of social, cultural, arts and educational activities to clients in primary care (known as 'social prescribing' or 'community linking schemes') as a means of addressing long-term physical health conditions and promoting mental health and well-being is becoming increasingly prominent and popular. However, concerns exist over a lack of evidence of effectiveness and formalised insights into how such initiatives may be optimally implemented. Methods: Within a case study design and using 1-1 semi-structured interviews, three related data sets were developed over a 12-month period from 30 purposively sampled informants: the project steering group; the wider primary care team; and various community groups. Data analysis drew on various theoretical resources, particularly those pertaining to nurturing sufficient capacity for the organisational 'normalisation' of this practice and understanding the dynamic flows and linkages between potential clients, 'prescribing' primary care staff and the available community resources. Findings: The inception and implementation of the initiative had been broadly successful and that more generally, there were grounds to suggest that these practices were becoming 'normalised' into the day-to-day cultures and routines of the primary care organisations. A series of procedural features are considered significant in achieving such ends. Some specific barriers to change are identified and ultimately in the context of potential 'transferability', a wider reflection is undertaken of the potential for such innovative practice to become established in less advantageous organisational circumstances. Fundamental difficulties are recognised and thus the need for formally implemented 'change' processes. Furthermore, for social prescribing to become a pervasive feature of health-care provision, the need for necessary capacity and resources is stressed.
\end{abstract}

Key words: implementation; social prescribing; sustainability

Received 12 October 2015; revised 5 May 2016; accepted 22 May 2016; first published online 8 June 2016

\section{Introduction}

The potential for primary care to 'rediscover' a 'social' model of practice (Olesen et al., 2000) and contribute to addressing social determinants of health (British Medical Association (BMA), 2011) and health inequalities (Marmot, 2008), respectively, is gaining increasing policy prominence.

Correspondence to: Sandy Whitelaw, Lecturer Health \& Social Policy, School of Interdisciplinary Studies, Dumfries Campus, University of Glasgow, Dumfries, DG1 4ZL. Email: alexander.whitelaw@glasgow.ac.uk 
In this context, and drawing on their role as 'community leaders' (BMA, 2011: 5), 'improv(ing) community capital and reduc(ing) social isolation' (Marmot, 2008: 24), the 'prescribing' of nonmedical activities to patients with long-term health conditions has increased significantly as an innovative practice (South et al., 2008).

Such work has a history - starting in the 1990s with 'exercise' (Lord and Green, 1995) moving onto 'arts' (Bungay and Clift, 2010) and more recently adopting the more comprehensive stance of prescribing a wider range of activities - 'social prescribing' (SP) (South et al., 2008) and has become associated with variously: 'up-stream' interventions (Hung et al., 2007); promoting 'well-being' (Friedli et al., 2009); encouraging 'self-management' (Scottish Government, 2013); and meeting the needs of 'disadvantaged' individuals in relation to issues such as isolation, redundancy and financial impoverishment (Cawston, 2011). Friedli et al. (2009) also suggests more pragmatic aspirations such as reducing demands for psychological services and cutting levels of psychotropic prescribing.

Two concepts underpin SP as a complex 'system' (Plsek and Greenhalgh, 2001) - linkage (Mossabir et al., 2014) and partnerships (Carlisle, 2010) between clients, primary care and community resources. Critically, realising such connections is recognised as difficult (Dickinson and Glasby, 2010) and despite gaining momentum, concerns exist over the paucity of evidence around optimal implementation processes and outcomes of SP (Brown et al., 2004); Mossabir et al. (2014) noting, 'very few ... schemes have been empirically evaluated' (Mossabir et al., 2014: 17) and that 'the mechanisms involved in the delivery of interventions ... remain unclear' (Mossabir et al., 2014: 1).

This paper addresses the latter area - undertaking a critical process-based evaluation of the design and implementation of a developmental SP initiative in the UK - Healthy Connections Stewartry $(H C S)$. This exercise was undertaken on the basis of a perception that project implementation, ultimate sustainability and further dissemination of learning is potentially enhanced by consciously attending to such processes. In this context, it provides an overview of the development and the early implementation of the $H C S$ initiative that has to this point seen 117 individual referrals into eight pathways. A series of data sets relating to varied domains have been maintained from the onset of the project and is on-going [referral numbers, measures of well-being (WEMWBS scale) and impacts on prescribing of minor tranquilisers and antidepressants].

\section{The HCS project}

The $H C S$ initiative was initiated in two purposively sampled (therefore very particular) General Practices (GP). These were chosen for their willingness to be involved in a 'test of change' process that sought to achieve the 'normalisation' (May et al., 2007) of SP activity into primary care. Stewartry district is located in Dumfries and Galloway, South West Scotland. It is rural in nature, with low population density and relatively high levels of isolation. Such circumstances and the difficulties of delivering accessible services provided a significant rationale for the SP model.

The project was underpinned by a multisector implementation group: the NHS (public health practitioners, GPs, Nurse Practitioner, Practice Manager and administrative staff); local government (Community Planning, Learning and Development) and 'community resources' (Council for Voluntary Service) and received initial funding as a 'test of change' from Putting You First (Local Reshaping Care Change Programme, which sought to encourage alternative forms of health care) as part of the Building Healthy Communities SelfManagement Programme. In practical terms, the enacted service design was based on a 'single point of contact' (SPOC) model wherein a 'SPOC link worker' made contact with the patient to assess and match their health and well-being needs with the available community resources and to subsequently facilitate and ultimately monitor this interaction.

The timeline for $H C S$ involved project initiation and preparatory background work (October 2011); instigation of a steering group and initial practical planning (July 2012); and commencement of referral work (May 2013) and comprised three elements. First, engagement with community agencies, identifying potential opportunities (eg, listening project, art opportunities, 'self-management' support, educational opportunities, financial advice, employability support and volunteering advice). Second, designing and implementing a referral process. Finally, developing and quality assuring the identified activities. Project evaluation matched 
these themes and forms the basis of the three strands of findings reported below. First, a review of early project planning (January-April 2013) with the research question "what has been the experience of key stakeholders of the initial development and implementation of HCS?' Then two parallel strands of work (January-April 2014): an analysis of the internal dynamics of two primary care centres, shaped by the research question, "what has been the experience of key primary care staff in the implementation of HCS?'; and an appraisal of the capacity of the community resources to fulfil HCS expectations using the research question, "what has been the experience of those within community resources in the implementation of HCS?'

\section{Implementing SP initiatives: pointers from the literature}

The initiative was consciously 'theoretically informed' (ICEBeRG, 2006) and the discussion below forms a context for subsequent empirical analysis. HCS was designed, implemented and evaluated using various resources: primarily, soft system theory (Checkland, 2000) complemented by concepts such as stepped 'change management' (from developing and communicating an early vision through to anchoring new approaches) (Moran and Avergun, 1997), nurturing features of 'capacity' (such as project leadership, strong partnerships, necessary resources and workforce development) (Potter and Brough, 2004) and ultimately, promoting 'sustainability' (Sibthorpe et al., 2005). Despite Mossabir et al.'s (2014) concerns over the poor evidence base surrounding SP implementation, the literature did provide insights into some relevant variables - both affirmatively (Brandling and House, 2009) and in relation to various 'barriers' (Checkland et al., 2007).

Affirmatively, Bungay and Clift (2010: 278) highlight the need for a supportive policy context. South et al. (2008: 316 ) also suggest that success is dependent on the active engagement of various community resources and strong links between them and project partners. The particular significance of the actions of agents in primary care has been noted (Sibthorpe et al., 2005: 77) and is often associated with fostering cultures of 'shared beliefs and values' (Marshall et al., 2002: 641).
Nurturing a set of organisational values supportive of a 'social model' of health is considered particularly important in embedding SP (Halfmann, 2011: 4).

A further set of insights exist around actual SP delivery. In the context of possible 'models' - from detached information-led initiatives to fully integrated approaches - most favour the latter; for example, South et al. (2008: 313) support an 'embedded' model with dedicated and skilled 'link-workers' within primary care. Mossabir et al. (2014) also highlight the significance of such workers as a 'single point' that regulates tripartite links between patients, primary care staff and community resources. The centrality of GPs in endorsing and engaging with SP activity is specifically recognised (White et al., 2010) as well as the engagement of the whole primary health-care team (Brandling and House, 2009).

Some potential 'barriers' are also suggested. Fundamentally, some feel that primary care may be relatively 'conservative' (Dale et al., 1997: 379) and that efforts to introduce innovation tend not to receive support (Ross and Kettles, 2012: 921). A series of more specific impediments are also highlighted, including poor understanding of the nature of SP (White et al., 2010); limited change resources (Goldberg et al., 2013); a poor evidence base (Bungay and Clift, 2010: 278); apprehension about referring to unknown community organisations (Mossabir et al., 2014); and scepticism arising from 'failed' previous referrals (Brandling and House, 2009).

Many of these themes can be accommodated in the analytical framework that we ultimately use to reflect on empirical experiences - May et al.'s (2007) 'normalisation theory' wherein 'normalising' practice would be associated with deeper and longer term sustainability. Three components are proposed: 'actors' (individuals and groups); 'objects' (expressions of change, such as policies, procedures and protocols) and 'contexts' (the environment around these processes). Furthermore, they postulate a series of processes: 'interactional workability' (quality of founding interactions); 'relational integration' (extent to which change relates to existing knowledge and positions); 'skill set workability' (extent to which 'change' skills are present); and 'contextual integration' (extent to which organisational features such as resources and policies support change). In combining these elements, May et al. hypothesise 
three possibilities - 'normalisation' (genuine embeddedness), 'adoption' (change achieved but not embedded) or 'rejection'.

\section{Methods}

In focusing on empirical implementation, our methodology drew on Fenwick's (2010: 104) 'sociomaterial' interest in 'enactments of work activity, politics and knowledge' and May et al.'s (2007: 150) 'normalisation process model' that suggest that implementation evaluation 'requires attention to ... processes by which ... interventions are made workable and integrated in everyday practice'. The complex nature of the circumstances suggested an 'interpretivist' approach Matthews and Ross (2010) within a case study design (Stake, 1995). Using a common method and analytical framework, the three strands were undertaken by three researchers from Glasgow University. Each purposively accessed informants: phase $1 \quad(n=12$ from the whole project steering group); phase 2 ( $n=10$ varied staff from the two primary care organisations, including GPs, Nurse Practitioner, Practice Manager and Receptionists); phase 3 ( $n=8$ from the varied community resources associated with the project). 1-1 semi-structured interviews were conducted along the following lines of enquiry: perceptions of the essential status of SP and $H C S$; views on the instigation and delivery of the initiative; reflections on the factors that are considered both conducive and restrictive to implementation and potentially longer term sustainability; and perceptions of the required capacity for prospective wider transferability. All interviews were transcribed, coded and thematically analysed (Boyatzis, 1998) with data and thematic rigour and credibility checks built in via the use of a critical friend within individual interview texts and wider collective scrutiny of emergent themes within the project steering group and the two practice teams (Rolfe, 2006). The work was given ethical approval from the Glasgow University Ethics Committee and informed consent was gained from all informants.

\section{Findings}

\section{Preliminary review: early project planning}

This phase offered insights into various aspects of the processes that underpinned the initial development of $H C S$. First, early engagement of a wide range of stakeholders was considered crucial, ensuring that all were knowledgeable of and motivated towards the project; a GP stating, 'I think the most positive element of the process is appropriate stakeholder involvement from day one'. Effective leadership and preparatory work from the Public Health practitioners was seen as the central feature of this instigation. This fostered the introduction of the basis of SP to the group that engendered relatively high levels of understanding and enthusiasm; a GP suggesting, 'that is the crux of partnership working ... you need ... some people who have that motivation, skills, that relationship to keep things going'.

This leadership also created a context in which almost all participants reported that $H C S$ had provided an open and responsive approach to contributions at partner meetings. The majority of stakeholders felt their views were incorporated into the planning process and a balanced approach to leadership had been achieved, summarised by a GP as 'we were led by leaders who had a very clear purpose ... but who allowed the meeting to develop in a natural way'. The most visible aspect of this process was high-quality partnership communication. Regular contact was maintained to ensure that all felt involved, something that was considered relatively unusual, a GP feeling, 'it has been refreshingly responsive to input from stakeholders ... and I think that was a somewhat unusual NHS development'. Similarly, some respondents appreciated the grounded orientation of the project; a GP stating, 'the focus is very practical'.

It was recognised that there was already a level of existing congruence within the primary care teams with the social ethos of SP and it was this commonality across partners that fostered interdisciplinary non-hierarchical working and early implementation. Such work led to partners feeling that they had a good understanding of the possible impacts and outcomes of SP at an early stage, for example, a GP stating, 'we all had a good idea of the aims and purpose'. In more functional terms, there was broad agreement that the stakeholder group was of a manageable size and consisted of the appropriate roles. It was however felt that two issues would have to be resolved: a broader spectrum of stakeholders would be needed at later stages, such as a wider range of prescribing staff, 
community service providers and possible endusers; and efforts would have to be made to 'quality assure' the community resources that patients were being referred into.

On the basis of the perceived favourability of these circumstances and the existences of very few critical or negative perspectives, it was decided to progress with the project.

\section{Primary care perspectives}

In keeping with the above, those within the wider primary care team felt involved and supported in the initiative and indeed some of the early concerns expressed above (predominantly about referring into community resources of unknown quality) were resolved. The nature of this involvement varied from strategic work in the planning group through to those who acted operationally as 'referrers'. While it was felt that the objectives of the project had been clearly communicated, informants also suggested that high levels of involvement and planning flexibility 'on the ground' had been advantageous - explaining that the project planners had been open to suggestions which in turn promoted ownership and enhanced the 'embedded' nature of change.
These circumstances led to the attainment of a series of conducive project features. First, in contrast to some studies that suggest the tendency for inefficient referral mechanisms leading to project failure (eg, Grol and Grimshaw, 2003), the ITbased referral process was seen as particularly efficient. This was the 'SCI Gateway' system - a national PC desktop-based IT exchange portal that facilitates clinical communication between primary and secondary care sources and potential referral sources. So in this case, the system variously allowed primary care staff immediate desktop access to the potential 'secondary' signposting routes; close communication and the effective transfer of patient data between primary care staff and the SPOC link worker; immediately usable information for the SPOC link worker to interact with the patient; and the potential to broadly monitor data and referrals. In terms of uptake and maintained use, this was a preferred option for GPs as the system was already central to their existing clinical work and offered high levels of confidentiality and data protection; a GP stating, 'SCI referral is very helpful because then it's just like any other referral'. The nature of this referral pathway is outlined below (Figure 1).

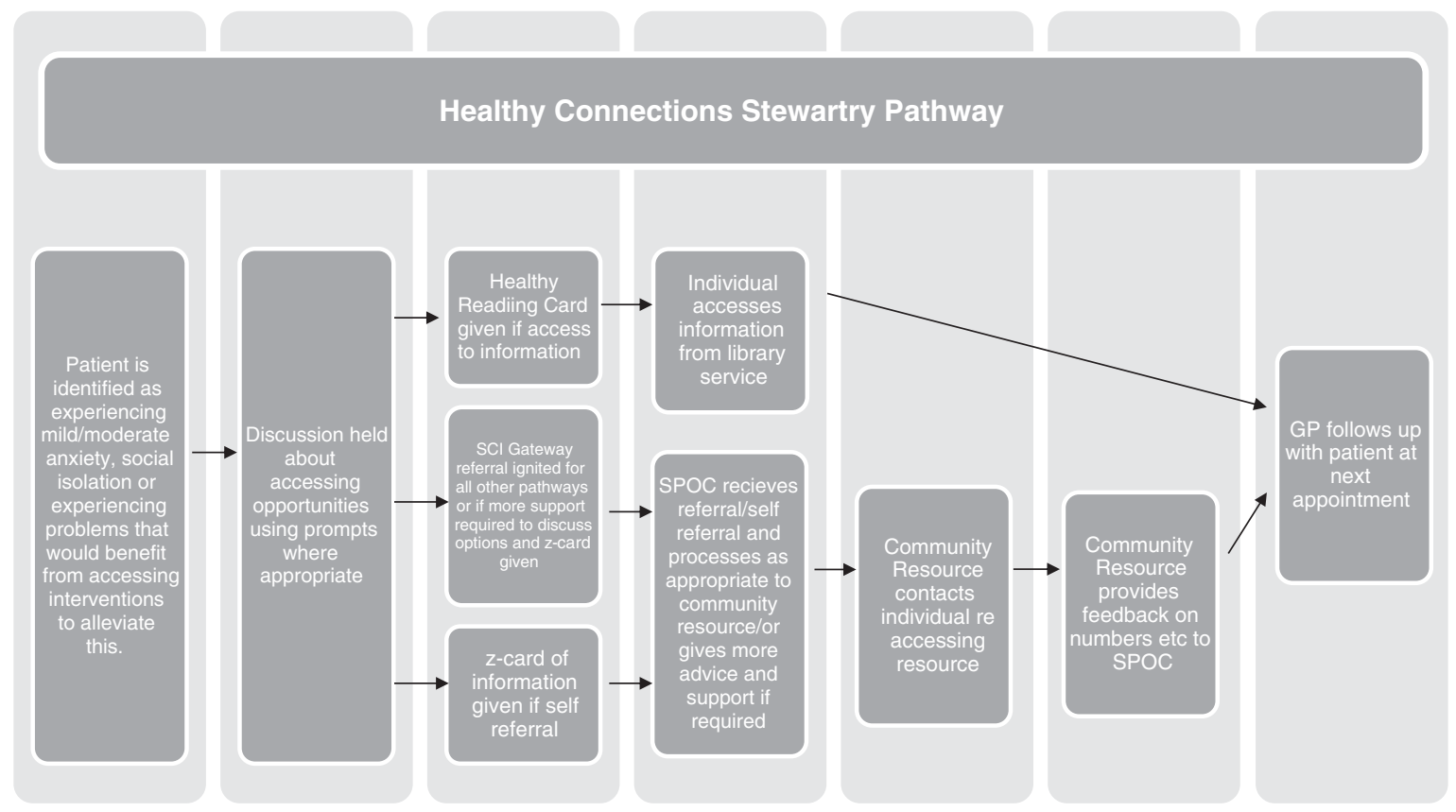

Figure 1 Healthy Connections Stewartry (HCS) referral pathway

Primary Health Care Research \& Development 2017; 18: 112-121 
A series of internal dynamics were also considered to have fostered adoption and potential normalisation. First, some suggested that they personally found participation in novel projects exciting and some informants felt that their practice was seen as an 'early-adopter' of innovation. Second, many held favourable perspectives towards a social model of primary care; a GP stating, 'my practice strives towards the ethos of holistic health care'. Some adopted this stance in relation to a critique of a 'medical model'; a GP for example suggesting, 'we need to get away from the narrowness of medical practice ... we do need to look at the people holistically within the society'. Furthermore, another GP felt that a 'demedicalised' approach had the potential to lead to a more effective and sustainable sector, it helps towards making the health service sustainable ... if it remains focused on the biomedical model ... it's unsustainable'. This theme reflected a belief among some that this re-alignment could be done on functional rather than idealistic or theoretical grounds - SP can be seen as being pragmatically useful in meeting client need and using resources more efficiently.

It should be noted though that some saw SP as an adjunct rather than an alternative, 'medical' and 'social' models to work together. This was particularly expressed in the context of addressing mental health difficulties; a Practice Manager informant suggesting, 'traditionally we differentiate the two ... health care and social care ... but I think that if we have a change of attitude and move towards a "care of health" banner ... then it conjures up a much more joined up approach'.

This positioning was seen not simply to be a function of professional preference but also shaped by patient expectations. While it was acknowledged that some had accepted the principle of SP and that a degree of targeting of patients had occurred (a GP stating, 'I haven't really suggested it to anyone who I didn't think would get something out of it'), informants felt that many patients expected medicalised care and any deviation potentially created resistance. The need to promote the idea of SP was therefore prominent; a Nurse Practitioner stating, 'we've always got to sell it to the patients'. In addition, some expressed the need for sensitivity over when to initiate discussion about the notion, a GP stating, 'maybe one of things we need to learn is when's the appropriate time to introduce this'.
This notion of foundations of effectiveness being partially outwith the control of primary care was expressed in relation to two themes - the significance of a wide range of high-quality community resources and the need for a strong volunteering based therein. Most informants highlighted the crucial status of community resources in the SP system and primarily linked this to the need for such resources to be funded on an on-going basis, a GP suggesting, 'you need to have recurring funding'. A Practice Manager informant was particularly pessimistic of achieving sustainability in the absence of such provision; "unless that funding stream continues the likelihood of it being sustainable it is negligible'. These issues were reflected upon in the context of UK primary care being 'semi-independent' from the state-funded NHS and the tendency for 'supplementary' practice (such as chronic condition management and health promotion) being resourced by 'top-up' funding governed by a 'Quality and Outcomes Framework' $(Q O F)$. This environment had created a view among some that one of the most powerful levers of fostering innovation was to include the activity in the QOF. Some informants felt that this mechanism had some potential in practices whose affinity towards SP was not strong, though on the basis of it being impractical and not an appropriate or even effective way of promoting change, most were against such a strategy. This was however complemented by a view that general funding for SP was required.

Some highlighted the importance of utilising a range of well-established community resources. The utility of relatively less established organisations was seen as more problematic and linked to a concern expressed about the robustness of such provision; for example, a GP felt 'I think there's a quality control side of things ... if we're actually posting people on ... then we're taking some responsibility'. Another GP felt that assuring confidentially was especially significant, '... confidentiality ... I think that's a big worry for doctors referring to non-NHS services'. Some informants suggested that there was a degree of sensitivity within the patient group about receiving support for mental health which in turn had made the groups reluctant to be part of HCS. A GP felt there was a 'fear of the unknown' among some groups, unsure if they might receive a patient with 'horrendous problems'. 
One specific area where implementation had been less successful was around the mechanisms for formal feedback to staff. As a significant motivational factor towards achieving sustainability, informants felt that getting information on the progress of the referral was 'good practice' and a simple prompt to use the service, a GP stating, 'just trying to keep remembering that you can refer people to it ... because there's nothing really to remind you because you're not getting letters or emails back from anybody saying "thanks for the referral"'. At this point, there was a general view that this communication could have been stronger; for example, a GP felt, 'there's been no feedback to the referrers'.

\section{Community resources perspectives}

Community resource informants broadly agreed that the concept of SP was valid, necessary and timely; for example, 'one of the things that's done my heart good ... was when $H C S$ came into being ... because it's been what's been needed'. Significantly, they saw their attributes as relevant in helping individuals to feel included and that inclusion could in turn provide a platform for enhancing well-being. It was felt that through $H C S$, there was greater opportunity for community resources to be more accessible to the wider community; for example, 'it wasn't until I realised that ... their job would be a lot easier if we could tackle things at grass roots'. Informants had a clear understanding of what their resource could offer; for example, 'people are stressed and excluded and feeling isolated and not able to connect to others $\ldots$ and this is a really good way to help to stop barriers'. In addition, the value of the social nature of interest groups and their relationship with fostering well-being was appreciated; for example, 'I've had quite a lot of referrals ... I've had one lady say to me that the two hours she spends in the group keeps her sane'.

Benefits for community resources were also identified. It was felt that an increase in referrals through HCS would benefit organisations with set targets linked to funding; for example, 'I get more people into the activities ... that's wonderful ... a lot of its numbers I'm afraid'. As well as this pragmatic benefit, informants felt that there had been deeper gains; 'it has worth ... I can think of one woman ... she says to me "you have saved my life".

Primary Health Care Research \& Development 2017; 18: 112-121
Barriers to engagement were however expressed. As with primary care colleagues, insufficient financial support was a consistent concern; for example, 'there has to be funding in place ... obviously I can't do this for free ... often you get funding for a short burst and then you can't have core funding anymore'. Furthermore, some felt that their organisation already had significant commitments and that further $H C S$ demand might be problematic; for example, 'we have not got a great amount of funds ... we are doing things for our own service users as well'. It was also felt that a lack of knowledge about HCS among the community may create a situation where only a limited number of organisations offer a referral pathway; for example, 'I don't think it's widely known about ... I think it could do with wider marketing'.

Informants also reflected on the potential for deeper and longer term sustainability. The overwhelming feeling was that for this to happen, a deeper shift would be required in both professional and patient perspectives - essentially a willingness from GPs to look to the wider community for solutions and for patients to accept this; for example, 'I think it's ideal $[H C S]$... it's maybe that it's a change for people ... the health professionals for them to get away from that normal way of going down that medical route' and in turn, that patients need to accept that a clinical or formal pathway is not their only option; for example, '(there are) people who are used to services ... the NHS will pick it up ... the Council will pick it up'.

In keeping with primary care informants, this group also highlighted the significance of maintaining a steady supply of quality-assured services through the training of skilled volunteers as a key element of sustainability. It was similarly felt that it was important for practitioners to know that they could confidently refer into services that were safe and reliable; for example, 'there needs to be a ... wider group of people that you know that you can safely refer to'.

\section{Discussion}

In purposively choosing a community and two GPs with conducive circumstances, this 'test of change' intervention was working within three normative positions - first, that high-quality community resources have the potential to contribute to the 
promotion of public mental health (Alcock, 2010); second, 'primary care' can be a particularly effective and equitable element of a wider health-care system (Starfield et al., 2005); and third, that this potential is particularly strong in circumstances that reflect holistic and social principles (Hung et al., 2007). In particular, given the significance of gaining the support of 'agents of change' in primary care and community resources (Sibthorpe et al., 2005: 77), the existence of supportive 'actors' (May et al., 2007) in HCS was particularly important. Despite the identified concerns, as a result of this intrinsic capacity combined with effective external support many of May et al.'s (2007) 'interactional', 'relational' and 'skill-based' requirements of change towards 'normalisation' were fulfilled. Mossabir et al.'s (2014) recognition of the specific need for GPs to have a prominent role was fulfilled in this case and this fostered further involvement of the wider primary care team. The status of a GP with 'early-adopter' status in the HCS planning group was considered particularly constructive and resulted in early 'small gains'. The theoretical barriers set out earlier potentially inhibiting adoption tended not to be expressed. Similarly, the enrolment of supportive local government and voluntary sector personnel with a willingness to engage with primary care and individuals referred from $H C S$ created accommodating circumstances.

This internal potential was complemented by various 'contextual' elements. With support derived from guidance such as the Mental Health Strategy for Scotland 2012-15 (Scottish Government, 2012) and Reshaping Care for Older People (Scottish Government/COSLA/NHS Scotland, 2011) the policy context for SP is increasingly conducive and this reinforced $H C S$. The leadership and co-ordination undertaken by the public health practitioners also fostered a series of internal requisites, including mobilising policy themes; securing 'pump priming' funding; engaging partners; and nurturing community resources. In combination, these elements formed what Moran and Avergun (1997) term a 'critical mass' for sustainability.

This combination cultivated what May et al. (2007) term, tangible 'objects'. A project 'form' soon became visible, reflecting many of the 'best practice' principles suggested by the likes of Brandling and House (2009) and South et al. (2008). That is, HCS adopted an 'active' model with a single point 'embedded' SP function. In addition, such structures were reflected in the creation of a series of what May et al. (2007) call 'objects', for example, the creation of an SPOC link worker and Health Improvement Officer posts; referral mechanisms/ pathways and protocols; presentations and papers to NHS D\&G committees; two peer-reviewed papers at national conferences; and recognition in national case study dissemination project.

One area where there was a view that such processes could have been enhanced was in relation to impact feedback. In relation to achieving sustainable change, Moran and Avergun's (1997) point to 'tracking and monitoring' as an important motivator for sustaining and embedding change and for some informants, more frequent and detailed response would have been appreciated.

One could conclude that in May et al.'s (2007) terms, HCS had achieved the status of 'adoption' (some change but not embedded) and is on the way to achieving 'normalised' embeddedness. Indeed, subsequent to this evaluation, further work has addressed identified critical issues - for example, improving the timeliness and quality of feedback and broadening the menu of available referral points. More broadly, in South et al.'s (2008: 316) terms, there is evidence that this SP model has acted as a vehicle to integrate public health into mainstream primary care' and more profoundly allows primary care to address 'the wider determinants of health through routine clinical services'.

\section{Conclusion}

We undertook this work believing that paying attention to processes was a significant aspect of understanding project implementation, achieving sustainability and possibly wider dissemination. Based on the significant numbers of patients being identified by GPs and successfully referred into community resources by the SPOC link worker, we can infer that attention to such issues has encouraged immediate inception and initial implementation.

Given the a priori favourability of circumstances, one should perhaps not be surprised at this relative 'success'. Indeed, given the extent of the planned development in this project, one might even have expected higher levels of assimilation 
and this perhaps supports Catford's (2009) recognition of the difficulty in achieving successful project 'delivery'. In this context, the potential for the transfer of successes to be less likely in 'hostile' circumstances cannot be ignored and concerns for wider translation recognised (Taylor et al., 2011).

However, in accepting the need for such 'top-loading', one should perhaps not be defensive about this conscious 'roll out' of innovation as a template for practice transfer and the project team are currently disseminating learning, seeking to foster similar SP activity in other GPs using insights from this work.

While South et al. (2008: 317) suggest that 'few would argue that SP is a magic bullet', they remain relatively optimistic about the value of the approach. This evaluation finds broad congruence with this position. It has shown that with sufficient time and the right prerequisites and processes, it is possible to successfully introduce and begin to embed SP into primary care. It also begins to suggest that it can be seen as part of a longer term re-orientation of health services and a vehicle that strengthens deeper relationships between primary care and various community resources.

\section{Acknowledgements}

The authors would like to thank those on the HCS Steering Group and everyone involved in the development and implementation of the initiative.

\section{References}

Alcock, P. 2010: Building the big society: a new policy environment for the third sector in England. Voluntary Sector Review 1, 379-89.

Boyatzis, R. 1998: Transforming qualitative information: thematic analysis and code development. Thousand Oaks, London, and New Delhi: Sage Publications..

Brandling, J. and House, W. 2009: Social prescribing in general practice: adding meaning to medicine. British Journal of General Practice 59, 454-56.

British Medical Association (BMA) 2011: Social determinants of health - what doctors can do. London: BMA.

Brown, M., Friedli, L. and Watson, S. 2004: Prescriptions for pleasure. Mental Health Today, June 1, pp. 20-23.

Bungay, H. and Clift, S. 2010: Arts on prescription: a review of practice in the UK. Perspectives in Public Health 130, $277-281$.

Primary Health Care Research \& Development 2017; 18: 112-121
Carlisle, S. 2010: Tackling health inequalities and social exclusion through partnership and community engagement? A reality check for policy and practice aspirations from a social inclusion partnership in Scotland. Critical Public Health 20, 117-27.

Catford, J. 2009: Advancing the 'science of delivery' of health promotion: not just the 'science of discovery'. Health Promotion International 21, 1-5.

Cawston, P. 2011: Social prescribing in very deprived areas. British Journal of General Practice 61, 350.

Checkland, K., Harrison, S. and Marshall, M. 2007: Is the metaphor of 'barriers to change' useful in understanding implementation? Evidence from general medical practice. Journal of Health Services Research and Policy 12, 95-100.

Checkland, P. 2000: Soft systems methodology: a thirty year retrospective. Systems Research and Behavioral Science Systems Research 17, S11-58.

Dale, B., Doaden, R., Wilcox, M. and McQuater, R. 1997: Sustaining total quality management: what are the key issues? The TQM Magazine 9, 372-80.

Dickinson, H. and Glasby, J. 2010: Why partnership working doesn't work. Public Management Review 12, 811-28.

Fenwick, T. 2010: Re-thinking the 'thing': sociomaterial approaches to understanding and researching learning in work. Journal of Workplace Learning 22, 104-16.

Friedli, L., Jackson, C., Abernethy, H. and Stansfield, J. 2009. Social prescribing for mental health: a guide to commissioning and delivery care services. Stockport: Improvement Partnership North West Development Centre.

Goldberg, D., Mick, S., Kuzel, A., Bo Feng, L. and Love, L. 2013: Why do some primary care practices engage in practice improvement efforts whereas others do not? Health Services Research 48, 389-416.

Grol, R. and Grimshaw, J. 2003: From best evidence to best practice: effective implementation of change in patients' care. The Lancet 362, 1225-230.

Halfmann, D. 2011: Recognizing medicalization and demedicalization: discourses, practices, and identities. Health 16, 186-207.

Hung, D., Rundall, T., Tallia, A., Cohen, D, Halpin, $\mathbf{H}$ and Crabtree, B. 2007: Rethinking prevention in primary care: applying the chronic care model to address health risk behaviors. Milbank Quarterly 85, 69-91.

ICEBeRG 2006: Designing theoretically-informed implementation interventions. Implementation Science 1, 4.

Lord, J. and Green, F. 1995: Exercise on prescription: does it work? Health Education Journal 54, 453-64.

Marmot, M. 2008: Fair society, healthy lives: the Marmot review. London: The Marmot Review.

Marshall, M., Sheaff, R., Rogers, A., Campbell, S., Halliwell, S., Pickard, S., Sibbald, B. and Roland, M. 2002: A qualitative study of the cultural change in primary care organisations needed to implement clinical governance. British Journal of General Practice 52, 641-45.

Matthews, B. and Ross, L. 2010: Research methods; a practical guide for the social sciences. London: Pearson Education. 
May, C., Finch, T., Mair, F., Ballini, L., Dowrick, C., Eccles, M., Gask, L., MacFarlane, A., Murray, E., Rapley, T., Rogers, A., Treweek, S., Wallace, P., Anderson, G., Burns, J. and Heaven, B. 2007: Understanding the implementation of complex interventions in health care: the normalization process model. BMC Health Services Research 7, 148.

Moran, J. and Avergun, A. 1997: Creating lasting change. The TQM Magazine 9, 146-51.

Mossabir, R., Morris, R., Kennedy, A., Blickem, C. and Rogers, A. 2014: A scoping review to understand the effectiveness of linking schemes from healthcare providers to community resources to improve the health and well-being of people with long-term conditions. Health and Social Care in the Community 23, 467-84.

Olesen, F., Dickinson, J. and Hjortdahl, P. 2000: General practice time for a new definition. British Medical Journal 320, 354-357.

Plsek, P.E. and Greenhalgh, T. 2001: Complexity science: the challenge of complexity in health care. British Medical Journal 323, 625-28.

Potter, C. and Brough, R. 2004: Systemic capacity building: a hierarchy of needs. Health Policy Planning 19, 336-345.

Rolfe, G. 2006: Validity, trustworthiness and rigour: quality and the idea of qualitative research. Journal of Advanced Nursing 53, 304-10.

Ross, J. and Kettles, A. 2012: Mental health nurse independent prescribing: what are nurse prescribers' views of the barriers to implementation? Journal of Psychiatric and Mental Health Nursing 19, 916-32.

Scottish Government 2011: Health of Scotland's population mental health. Edinburgh: Scottish Government.

Scottish Government 2012: Mental health strategy for Scotland 2012-2015. Edinburgh: Scottish Government.

Scottish Government 2013: Route map to the 2020 vision for health and social care. Edinburgh: Scottish Government.

Scottish Government/COSLA/NHS Scotland 2011: Reshaping care for older people: a programme for change. Edinburgh: Scottish Government.

Sibthorpe, B., Glasgow, N. and Wells, R. 2005: Emergent themes in sustainability of primary health care innovation. The Medical Journal of Australia 183, 77-80.

South, J., Higgins, T., Woodall, J. and White, S. 2008: Can social prescribing provide the missing link? Primary Health Care Research and Development 9, 310-18.

Stake, R. 1995: The art of case study. London: Research Sage.

Starfield, B, Shi, L. and Macinko, J. 2005: Contribution of primary care to health systems and health. Milbank Quarterly 83, 457-502.

Taylor, B., Mathers, J., Atfield, T. and Parry, J. 2011: What are the challenges to the big society in maintaining lay involvement in health improvement, and how can they be met? Journal of Public Health 33, 5-10.

White, J., Kinsella, K. and South, J. 2010: An evaluation of social prescribing health trainers in South and West Bradford. Leeds: Leeds Metropolitan University. 